\title{
Further results on the asymptotic stability of Riemann-Liouville fractional neutral systems with variable delays
}

Yener Altun ${ }^{1 *}$ (1)

"Correspondence:

yener_altun@yahoo.com

${ }^{1}$ Ercis Management Faculty,

Department of Business

Administration, Yuzuncu Yil

University, Van, Turkey

\section{第 Springer}

\begin{abstract}
In this paper, the investigation of the asymptotic stability of Riemann-Liouville fractional neutral systems with variable delays has been presented. The advantage of the Lyapunov functional was used to achieve the desired results. The stability criteria obtained for zero solution of the system were formulated as linear matrix inequalities (LMIs) which can be easily solved. The advantage of the considered method is that the integer-order derivatives of the Lyapunov functionals can be directly calculated. Finally, three numerical examples have been evaluated to illustrate that the proposed method is flexible and efficient in terms of computation and to demonstrate the feasibility of established assumptions by MATLAB-Simulink.
\end{abstract}

MSC: 34K20; 34K37; 34K40

Keywords: Asymptotic stability; Riemann-Liouville fractional neutral systems; Lyapunov functional; LMI; Variable delay

\section{Introduction}

Fractional calculus and fractional differential systems have been of considerable interest for the past few decades. It has been proved that fractional-order calculus is more adequate and general to describe real world problems than the integer calculus. Therefore, not only mathematicians have currently had a robust interest in the fractional calculus. At the same time, it is seen that fractional systems without or with time-varying delays often occur in many scientific areas such as engineering techniques fields, physics, polymer rheology, regular variation in thermodynamics, biophysics, blood flow phenomena, capacitor theory, electrical circuits, signal processing, biology, control theory, etc. (see [1-28] and the references therein). There are some studies in the literature including recent developments in the field of the fractional calculus as well as its applications such as the model of spring pendulum in fractional sense $[2,4,11]$.

On the other hand, the interest in stability analysis of various fractional neutral differential systems has been growing rapidly due to their successful applications in widespread fields of science and engineering $[19,22]$. In this direction, the stability issue for considered systems is one of the important problems in case of theoretical and practical applications. It is clear that the analysis on the stability of fractional-order systems has a more complex

(c) The Author(s) 2019. This article is distributed under the terms of the Creative Commons Attribution 4.0 International License (http://creativecommons.org/licenses/by/4.0/), which permits unrestricted use, distribution, and reproduction in any medium, provided you give appropriate credit to the original author(s) and the source, provide a link to the Creative Commons license, and indicate if changes were made. 
structure than that of classical differential equations due to the fractional derivatives that are nonlocal and have weakly singular kernels $[5,14]$.

It is also known that fractional neutral systems have a more general class than those of the delayed type. The stability of neutral systems proves to be a more complex question because the system includes the derivative of the retarded state. When the related literature is searched, especially in the past few years, increased attention has been devoted to the problem of delay dependent or independent stability via different approaches for fractional neutral systems. But until now, only a few studies have been published for investigation of the stability of fractional neutral systems. However, there are many studies on the stability of neutral systems in differential equations/systems (see [29-33] and the references therein). It is seen that the stability method in most of the studies related to the stability of the systems in the control theory is based on LMI and the classical Lyapunov stability theory such as in $[9,13-20,25,34-38]$. In this study, the technique of the proof involves some basic inequalities, LMIs, and Lyapunov functional method.

Motivated by the above discussions, in this paper we deal with the asymptotic stability of Riemann-Liouville fractional neutral systems. Compared to integer-order neutral systems with variable delays, the research on the stability of fractional-order neutral systems is still at the stage of exploiting and developing. The main purpose and contribution of this study are listed as follows:

(i) In general, there are a few practical algebraic criteria on stability of fractional-order delayed systems in the current literature. The main reason for this fact is that it is very difficult to calculate the fractional-order derivatives of Lyapunov functionals $[14,16,19,28]$. The advantage of our method is that the integer-order derivatives of the Lyapunov functionals can be directly calculated. Therefore, we do not need to calculate fractional-order derivative of the Lyapunov functional. The obtained stability criteria are defined as LMIs, which are also convenient and feasible to test the asymptotic stability of the addressed fractional neutral systems;

(ii) The considered system includes state variable delays, fractional-order derivatives of the states, and variable delays in fractional-order derivatives of states. We have taken into account the effect of these components on the stability of a neutral system simultaneously. The presented results contribute to the Riemann-Liouville fractional-order neutral systems. Also, we give three examples with numerical simulations to illustrate the effectiveness of theoretical results;

(iii) Compared to the existing results concerning integer-order neutral systems [30-33] and fractional-order neutral systems $[13,16,20]$ with variable delays, the results of this paper are more general and less conservative. We think that this study will contribute to the related literature, and it may be useful for researchers working on the qualitative behavior of solutions.

The rest of this paper is organized as follows: The problem formulation and some needed assumptions are presented in Sect. 2. The main results of the study, that is, sufficient conditions for asymptotic stability and some assumptions throughout the study and synthesis of the system under consideration, are included in Sect. 3. In Sect. 4, three numerical examples with simulations are shown to illustrate the effectiveness of the solution of the proposed fractional equation system, and the article is finalized with Sect. 5.

Throughout this work, the following notations will be used. $\Re^{n}$ denotes the $n$ dimensional Euclidean space; $\Re^{n \times n}$ is the set of all $n \times n$ real matrices; $\|\cdot\|$ denotes 
the Euclidean norm for vectors; let $C=C\left([-h, 0], R^{n}\right)$ be the space of piecewise continuous differentiable functions from $[-h, 0]$ to $R^{n} ; A^{T}$ means the transpose of the matrix $A ; B$ is symmetric if $B=B^{T} ; H$ is positive definite (or negative definite) if $\langle H x, x\rangle>0$ (or $\langle H x, x\rangle<0)$ for all $x \neq 0 ;\|D\|$ denotes the spectral norm of matrix $D ; \lambda_{\min }(A)$ and $\lambda_{\max }(A)$ denote the minimal and maximal eigenvalue of the matrix $A$, respectively.

\section{Problem description}

In this study, we consider the following fractional neutral system with variable delays:

$$
{ }_{t_{0}} D_{t}^{q} x(t)-C_{t_{0}} D_{t}^{q} x(t-h(t))=A_{0} x(t)+A_{1} x(t-h(t))+B \int_{t-h(t)}^{t} x(s) d s, \quad t \geq 0,
$$

with the initial conditions

$$
{ }_{t_{0}} D_{t}^{-(1-q)} x(t)=\vartheta(t), \quad t \in[-h, 0],
$$

where $0<q<1,{ }_{t_{0}} D_{t}^{q} x(\cdot)$ shows a $q$ order Riemann-Liouville fractional derivative of $x(\cdot)$, $x(t) \in \mathfrak{R}^{n}$ is the state vector, $A_{0}, A_{1}, B, C \in \Re^{n \times n}$ are known constant matrixes, and $h(t)$ is a variable delay function.

For $h(t)$ variable delay, we assume that there are two different cases as follows:

Case $I$. $h(t)$ is a differentiable function satisfying, for all $t \geq 0$,

$$
0 \leq h(t) \leq h \quad \text { and } \quad \dot{h}(t) \leq \delta<1 .
$$

Case II. $h(t)$ is not differentiable or the upper bound of the derivative of $h(t)$ is unknown, and $h(t)$ holds for all $t \geq 0$,

$$
0 \leq h(t) \leq h,
$$

where $h$ and $\delta$ are nonnegative constants.

Before evaluating the main result, some basic definitions of fractional analysis and important lemmas are needed as given below.

Definition 2.1 ([23]) The Riemann-Liouville fractional integral is described as

$$
{ }_{t_{0}} D_{t}^{-q} x(t)=\frac{1}{\Gamma(q)} \int_{t_{0}}^{t}(t-s)^{q-1} x(s) d s \quad(q>0) .
$$

Definition 2.2 ([23]) The Riemann-Liouville fractional derivative is described as

$$
{ }_{t_{0}} D_{t}^{q} x(t)=\frac{1}{\Gamma(n-q)} \frac{d^{n}}{d t^{n}} \int_{t_{0}}^{t} \frac{x(s)}{(t-s)^{q+1-n}} d s \quad(n-1 \leq q<n),
$$

where $\Gamma$ denotes the gamma function.

Lemma 2.1 ([12]) If $p>q>0$, then the formula

$$
{ }_{t_{0}} D_{t}^{q}\left({ }_{t_{0}} D_{t}^{-p} x(t)\right)={ }_{t_{0}} D_{t}^{q-p} x(t)
$$


holds for "sufficiently good" functions $x(t)$. In particular, this relation holds if $x(t)$ is integrable.

Lemma 2.2 ([9]) Let $x(t) \in \Re^{n}$ be a vector of differentiable function for $\forall t \geq t_{0}$. Then the following relationship holds:

$$
\frac{1}{2} t_{0} D_{t}^{q}\left(x^{T}(t) M x(t)\right) \leq x^{T}(t) M_{t_{0}} D_{t}^{q} x(t), \quad 0<q<1,
$$

where $M \in \mathfrak{R}^{n \times n}$ is a constant, square, symmetric, and positive semi-definite matrix.

Lemma 2.3 ([33]) For all symmetric positive definite matrix $S \in D^{n \times n}$, scalar $\gamma>0$, and vector function $g:[0, \gamma] \rightarrow R^{n}$, such that the integrations in the following inequality are well defined, we have

$$
\gamma \int_{0}^{\gamma} g^{T}(s) S g(s) d s \geq\left[\int_{0}^{\gamma} g(s) d s\right]^{T} S\left[\int_{0}^{\gamma} g(s) d s\right] .
$$

\section{Main results}

In order to simplify the treatment of the problem, the operator $L: C\left([-h, 0], R^{n}\right) \rightarrow R^{n}$ is defined to be $L: L\left(x_{t}\right)=x(t)-C x(t-h(t))$.

The stability of the operator $L$ is described as follows.

Definition 3.1 ([10]) The operator $L$ is said to be stable if the zero solution of the homogeneous difference equation $L\left(x_{t}\right)=0, t \geq 0$, is uniformly asymptotically stable.

Lemma 3.1 ([10]) The operator $L$ is stable if $\|C\|<1$.

In the following Theorems 3.1-3.3, we give our main results for the fractional neutral system (2.1).

Theorem 3.1 Under Case I, the zero solution of system (2.1) with (2.2) is asymptotically stable if $\|C\|<1$, and there exist symmetric positive definite matrices $P, Q, R, S$, and $U$ such that the following LMI holds:

$$
\Omega=\left[\begin{array}{llll}
\Omega_{11} & \Omega_{12} & \Omega_{13} & \Omega_{14} \\
\Omega_{12}^{T} & \Omega_{22} & \Omega_{23} & \Omega_{24} \\
\Omega_{13}^{T} & \Omega_{23}^{T} & \Omega_{33} & \Omega_{34} \\
\Omega_{14}^{T} & \Omega_{24}^{T} & \Omega_{34}^{T} & \Omega_{44}
\end{array}\right]<0
$$

where

$$
\begin{aligned}
& \Omega_{11}=P A_{0}+A_{0}^{T} P+Q+h^{2} S+A_{0}^{T}\left(R+h^{2} U\right) A_{0}, \quad \Omega_{12}=P A_{1}+A_{0}^{T}\left(R+h^{2} U\right) A_{1}, \\
& \Omega_{13}=P B+A_{0}^{T}\left(R+h^{2} U\right) B, \quad \Omega_{14}=P C+A_{0}^{T}\left(R+h^{2} U\right) C, \\
& \Omega_{22}=A_{1}^{T}\left(R+h^{2} U\right) A_{1}-(1-\delta) Q, \quad \Omega_{23}=A_{1}^{T}\left(R+h^{2} U\right) B, \\
& \Omega_{24}=A_{1}^{T}\left(R+h^{2} U\right) C, \quad \Omega_{33}=-S+B^{T}\left(R+h^{2} U\right) B, \quad \Omega_{34}=B^{T}\left(R+h^{2} U\right) C, \\
& \Omega_{44}=C^{T}\left(R+h^{2} U\right) C-(1-\delta) R .
\end{aligned}
$$


Proof Let us consider the following Lyapunov functional for fractional neutral system (2.1):

$$
V(t)=\sum_{k=1}^{3} V_{k}(t), \quad t \geq 0,
$$

where

$$
\begin{aligned}
& V_{1}(t)=t_{0} D_{t}^{q-1}\left(x^{T}(t) P x(t)\right), \\
& V_{2}(t)=\int_{t-h(t)}^{t} x^{T}(s) Q x(s) d s+\int_{-h(t)}^{0}\left(t_{0} D_{t}^{q} x(t+s)\right)^{T} R\left(t_{0} D_{t}^{q} x(t+s)\right) d s, \\
& V_{3}(t)=h \int_{-h}^{0} \int_{t+\beta}^{t} x^{T}(s) S x(s) d s d \beta+h \int_{-h}^{0} \int_{t+\beta}^{t}\left({ }_{t_{0}} D_{s}^{q} x(s)\right)^{T} U\left({ }_{t_{0}} D_{s}^{q} x(s)\right) d s d \beta .
\end{aligned}
$$

From Definitions 2.1 and 2.2, we know that $V_{1}(t), V_{2}(t)$, and $V_{3}(t)$ are positive definite functionals. It follows from (2.2) and Lemmas 2.1 and 2.2 that we get the time derivative $V(t)$ along the trajectories of fractional system (2.1) as follows:

$$
\dot{V}(t)=\sum_{k=1}^{3} \dot{V}_{k}(t),
$$

where

$$
\begin{aligned}
\dot{V}_{1}(t)= & { }_{0} D_{t}^{q}\left(x^{T}(t) P x(t)\right) \\
\leq & 2 x^{T}(t) P_{t_{0}} D_{t}^{q}(x(t)) \\
= & 2 x^{T}(t) P\left[A_{0} x(t)+A_{1} x(t-h(t))+B \int_{t-h(t)}^{t} x(s) d s+C_{t_{0}} D_{t}^{q} x(t-h(t))\right] \\
= & x^{T}(t)\left(P A_{0}+A_{0}^{T} P\right) x(t)+2 x^{T}(t) P A_{1} x(t-h(t))+2 x^{T}(t) P B \int_{t-h(t)}^{t} x(s) d s \\
& +2 x^{T}(t) P C_{t_{0}} D_{t}^{q} x(t-h(t)), \\
\dot{V}_{2}(t)= & x^{T}(t) Q x(t)-(1-\dot{h}(t)) x^{T}(t-h(t)) Q x(t-h(t))+\left(t_{0} D_{t}^{q} x(t)\right)^{T} R\left(t_{0} D_{t}^{q} x(t)\right) \\
& -(1-\dot{h}(t))\left(t_{0} D_{t}^{q} x(t-h(t))\right)^{T} R\left({ }_{t_{0}} D_{t}^{q} x(t-h(t))\right) \\
\leq & x^{T}(t) Q x(t)-(1-\delta) x^{T}(t-h(t)) Q x(t-h(t))+\left({ }_{t_{0}} D_{t}^{q} x(t)\right)^{T} R\left(t_{0} D_{t}^{q} x(t)\right) \\
& -(1-\delta)\left({ }_{t_{0}} D_{t}^{q} x(t-h(t))\right)^{T} R\left({ }_{t_{0}} D_{t}^{q} x(t-h(t))\right), \\
\dot{V}_{3}(t)= & h^{2} x^{T}(t) S x(t)-h \int_{t-h}^{t} x^{T}(s) S x(s) d s+h^{2}\left({ }_{t_{0}} D_{t}^{q} x(t)\right)^{T} U\left({ }_{t_{0}} D_{t}^{q} x(t)\right) \\
& -h \int_{t-h}^{t}\left(t_{0} D_{s}^{q} x(s)\right)^{T} U\left({ }_{t_{0}} D_{s}^{q} x(s)\right) d s \\
\leq & h^{2} x^{T}(t) S x(t)-h \int_{t-h}^{t} x^{T}(s) S x(s) d s+h^{2}\left({ }_{t_{0}} D_{t}^{q} x(t)\right)^{T} U\left({ }_{t_{0}} D_{t}^{q} x(t)\right) .
\end{aligned}
$$


Obviously, for any scalars $\in[t-h, t]$, and by Lemma 2.3 , we have

$$
\begin{aligned}
-h \int_{t-h}^{t} x^{T}(s) S x(s) d s & \leq-h \int_{t-h(t)}^{t} x^{T}(s) S x(s) d s \\
& \leq-\left(\int_{t-h(t)}^{t} x(s) d s\right)^{T} S\left(\int_{t-h(t)}^{t} x(s) d s\right) .
\end{aligned}
$$

Taking into account (3.4) and (3.5), we get

$$
\begin{aligned}
& \left({ }_{t_{0}} D_{t}^{q} x(t)\right)^{T} R\left({ }_{t_{0}} D_{t}^{q} x(t)\right)+h^{2}\left({ }_{t_{0}} D_{t}^{q} x(t)\right)^{T} U\left({ }_{t_{0}} D_{t}^{q} x(t)\right) \\
& =\left[A_{0} x(t)+A_{1} x(t-h(t))+B \int_{t-h(t)}^{t} x(s) d s+C_{t_{0}} D_{t}^{q} x(t-h(t))\right]^{T}\left(R+h^{2} U\right) \\
& \times\left[A_{0} x(t)+A_{1} x(t-h(t))+B \int_{t-h(t)}^{t} x(s) d s+C_{t_{0}} D_{t}^{q} x(t-h(t))\right] \\
& =x^{T}(t) A_{0}^{T}\left(R+h^{2} U\right) A_{0} x(t)+x^{T}(t) A_{0}^{T}\left(R+h^{2} U\right) A_{1} x(t-h(t)) \\
& +x^{T}(t) A_{0}^{T}\left(R+h^{2} U\right) B \int_{t-h(t)}^{t} x(s) d s+x^{T}(t) A_{0}^{T}\left(R+h^{2} U\right) C_{t_{0}} D_{t}^{q} x(t-h(t)) \\
& +x^{T}(t-h(t)) A_{1}^{T}\left(R+h^{2} U\right) A_{0} x(t)+x^{T}(t-h(t)) A_{1}^{T}\left(R+h^{2} U\right) A_{1} x(t-h(t)) \\
& +x^{T}(t-h(t)) A_{1}^{T}\left(R+h^{2} U\right) B \int_{t-h(t)}^{t} x(s) d s \\
& +x^{T}(t-h(t)) A_{1}^{T}\left(R+h^{2} U\right) C_{t_{0}} D_{t}^{q} x(t-h(t)) \\
& +\left(\int_{t-h(t)}^{t} x(s) d s\right)^{T} B^{T}\left(R+h^{2} U\right) A_{0} x(t) \\
& +\left(\int_{t-h(t)}^{t} x(s) d s\right)^{T} B^{T}\left(R+h^{2} U\right) A_{1} x(t-h(t)) \\
& +\left(\int_{t-h(t)}^{t} x(s) d s\right)^{T} B^{T}\left(R+h^{2} U\right) B \int_{t-h(t)}^{t} x(s) d s \\
& +\left(\int_{t-h(t)}^{t} x(s) d s\right)^{T} B^{T}\left(R+h^{2} U\right) C_{t_{0}} D_{t}^{q} x(t-h(t)) \\
& +\left({ }_{t_{0}} D_{t}^{q} x(t-h(t))\right)^{T} C^{T}\left(R+h^{2} U\right) A_{0} x(t) \\
& +\left({ }_{t_{0}} D_{t}^{q} x(t-h(t))\right)^{T} C^{T}\left(R+h^{2} U\right) A_{1} x(t-h(t)) \\
& +\left({ }_{t_{0}} D_{t}^{q} x(t-h(t))\right)^{T} C^{T}\left(R+h^{2} U\right) B \int_{t-h(t)}^{t} x(s) d s \\
& +\left({ }_{t_{0}} D_{t}^{q} x(t-h(t))\right)^{T} C^{T}\left(R+h^{2} U\right) C_{t_{0}} D_{t}^{q} x(t-h(t)) .
\end{aligned}
$$

From (3.3)-(3.7), we obtain

$$
\dot{V}(t) \leq \eta^{T}(t) \Omega \eta(t)
$$


where

$$
\eta^{T}=\left[\begin{array}{llll}
x^{T}(t) & x^{T}(t-h(t)) & \left(\int_{t-h(t)}^{t} x(s) d s\right)^{T} & \left({ }_{t_{0}} D_{t}^{q} x(t-h(t))\right)^{T}
\end{array}\right]
$$

and $\Omega$ is defined in (3.1). If $\Omega<0, \dot{V}(t)$ is negative definite for $\eta(t) \neq 0$. This implies that the system fractional (2.1) is asymptotically stable. Thus, the proof is complete.

Remark 3.1 A new criterion on delay-independent stability will be obtained if we choose a different Lyapunov functional.

Theorem 3.2 Under Case I, the zero solution of system (2.1) with (2.2) is asymptotically stable if $\|C\|<1$, and there exist symmetric positive definite matrices $P, Q, S$, and $U$ such that the following LMI holds:

$$
\begin{aligned}
\Sigma & =\left[\begin{array}{ccc}
P A_{0}+A_{0}^{T} P+Q+h^{2} S+h^{2} A_{0}^{T} U A_{0} & P A_{1}-A_{0}^{T} P C+h^{2} A_{0}^{T} U A_{1} & P B+h^{2} A_{0}^{T} U B \\
A_{1}^{T} P-C^{T} P A_{0}+h^{2} A_{1}^{T} U A_{0} & h^{2} A_{1}^{T} U A_{1}-2 C^{T} P A_{1}-(1-\delta) Q & h^{2} A_{1}^{T} U B-C^{T} P B \\
B^{T} P+h^{2} B^{T} U A_{0} & h^{2} B^{T} U A_{1}-B^{T} P C & h^{2} B^{T} U B-S
\end{array}\right] \\
& <0 .
\end{aligned}
$$

Proof Let us consider the following Lyapunov functional for fractional neutral system (2.1):

$$
\begin{aligned}
W(t)= & t_{0} D_{t}^{q-1}\left(\left(L\left(x_{t}\right)\right)^{T} P\left(L\left(x_{t}\right)\right)\right)+\int_{t-h(t)}^{t} x^{T}(s) Q x(s) d s+h \int_{-h}^{0} \int_{t+\beta}^{t} x^{T}(s) S x(s) d s d \beta \\
& +h \int_{-h}^{0} \int_{t+\beta}^{t}\left(t_{0} D_{s}^{q}\left(L\left(x_{s}\right)\right)^{T} U\left({ }_{t_{0}} D_{s}^{q}\left(L\left(x_{s}\right)\right)\right) d s d \beta .\right.
\end{aligned}
$$

It follows from (2.2) and Lemmas 2.1 and 2.2 that we get the time derivative $W(t)$ along the trajectories of system (2.1) as follows:

$$
\begin{aligned}
\dot{W}(t) \leq & 2(x(t)-C x(t-h(t)))^{T} P\left[A_{0} x(t)+A_{1} x(t-h(t))+B \int_{t-h(t)}^{t} x(s) d s\right] \\
& +x^{T}(t) Q x(t)-(1-\dot{h}(t)) x^{T}(t-h(t)) Q x(t-h(t)) \\
& +h^{2} x^{T}(t) S x(t)-h \int_{t-h}^{t} x^{T}(s) S x(s) d s \\
& +h^{2}\left({ }_{t_{0}} D_{t}^{q}(x(t)-C x(t-h(t)))\right)^{T} U\left({ }_{t_{0}} D_{t}^{q}(x(t)-C x(t-h(t)))\right) \\
& -h \int_{t-h}^{t}\left(t_{0} D_{s}^{q}(x(s)-C x(s-h(s)))\right)^{T} U\left(t_{0} D_{t}^{q}(x(s)-C x(s-h(s)))\right) d s \\
\leq & x^{T}(t)\left(P A_{0}+A_{0}^{T} P\right) x(t)+2 x^{T}(t) P A_{1} x(t-h(t))+2 x^{T}(t) P B \int_{t-h(t)}^{t} x(s) d s \\
& -2 x^{T}(t-h(t)) C^{T} P A_{0} x(t)-2 x^{T}(t-h(t)) C^{T} P A_{1} x(t-h(t)) \\
& -2 x^{T}(t-h(t)) C^{T} P B \int_{t-h(t)}^{t} x(s) d s+x^{T}(t) Q x(t) \\
& -(1-\delta) x^{T}(t-h(t)) Q x(t-h(t))+h^{2} x^{T}(t) S x(t)-h \int_{t-h}^{t} x^{T}(s) S x(s) d s
\end{aligned}
$$




$$
\begin{aligned}
& +h^{2} x^{T}(t) A_{0}^{T} U A_{0} x(t)+h^{2} x^{T}(t) A_{0}^{T} U A_{1} x(t-h(t)) \\
& +h^{2} x^{T}(t) A_{0}^{T} U B \int_{t-h(t)}^{t} x(s) d s+h^{2} x^{T}(t-h(t)) A_{1}^{T} U A_{0} x(t) \\
& +h^{2} x^{T}(t-h(t)) A_{1}^{T} U A_{1} x(t-h(t))+h^{2} x^{T}(t-h(t)) A_{1}^{T} U B \int_{t-h(t)}^{t} x(s) d s \\
& +h^{2}\left(\int_{t-h(t)}^{t} x(s) d s\right)^{T} B^{T} U A_{0} x(t)+h^{2}\left(\int_{t-h(t)}^{t} x(s) d s\right)^{T} B^{T} U A_{1} x(t-h(t)) \\
& +h^{2}\left(\int_{t-h(t)}^{t} x(s) d s\right)^{T} B^{T} U B \int_{t-h(t)}^{t} x(s) d s .
\end{aligned}
$$

Obviously, for any scalar $s \in[t-h, t]$, and by Lemma 2.3 , we have

$$
\begin{aligned}
-h \int_{t-h}^{t} x^{T}(s) S x(s) d s & \leq-h \int_{t-h(t)}^{t} x^{T}(s) S x(s) d s \\
& \leq-\left(\int_{t-h(t)}^{t} x(s) d s\right)^{T} S\left(\int_{t-h(t)}^{t} x(s) d s\right) .
\end{aligned}
$$

From (3.10) and (3.11), we obtain

$$
\dot{W}(t) \leq \xi^{T}(t) \Sigma \xi(t)
$$

where

$$
\xi^{T}=\left[\begin{array}{lll}
x^{T}(t) & x^{T}(t-h(t)) & \left(\int_{t-h(t)}^{t} x(s) d s\right)^{T}
\end{array}\right]
$$

and $\Sigma$ is defined in (3.8). If $\Sigma<0, \dot{W}(t)$ is negative definite for $\xi(t) \neq 0$. This implies that system (2.1) is asymptotically stable. Thus, the proof is complete.

Theorem 3.3 Under Case II, the zero solution of system (2.1) with (2.3) is asymptotically stable if $\|C\|<1$, and there exist symmetric positive definite matrices $P, S$, and $U$ such that the following LMI holds:

$$
\begin{aligned}
\Xi & =\left[\begin{array}{ccc}
P A_{0}+A_{0}^{T} P+h^{2} S+h^{2} A_{0}^{T} U A_{0} & P A_{1}-A_{0}^{T} P C+h^{2} A_{0}^{T} U A_{1} & P B+h^{2} A_{0}^{T} U B \\
A_{1}^{T} P-C^{T} P A_{0}+h^{2} A_{1}^{T} U A_{0} & h^{2} A_{1}^{T} U A_{1}-2 C^{T} P A_{1} & h^{2} A_{1}^{T} U B-C^{T} P B \\
B^{T} P+h^{2} B^{T} U A_{0} & h^{2} B^{T} U A_{1}-B^{T} P C & h^{2} B^{T} U B-S
\end{array}\right] \\
& <0 .
\end{aligned}
$$

Proof In Case II, a Lyapunov functional can be chosen as (3.9) with $Q=0$. Similar to the above analysis, one can get that $\dot{W}(t)<0$ holds if $\Xi<0$. Thus, the proof of Theorem 3.3 is complete.

\section{Numerical examples and simulation results}

To illustrate the effectiveness and applicability of the proposed method, the following three numerical examples are presented. 
Example 4.1 As a special case of system (2.1), consider the following fractional neutral system with variable delay:

$$
{ }_{t_{0}} D_{t}^{q}(x(t)-C x(t-h(t)))=A_{0} x(t)+A_{1} x(t-h(t))+B \int_{t-h(t)}^{t} x(s) d s, \quad t \geq 0
$$

where $q \in(0,1), x(t)=\left[x_{1}(t), x_{2}(t)\right]^{T}$,

$$
\begin{array}{ll}
A_{0}=\left[\begin{array}{cc}
-4 & 3 \\
0 & -2
\end{array}\right], & A_{1}=\left[\begin{array}{cc}
0.3 & 0.2 \\
0 & 0.2
\end{array}\right], \\
B=\left[\begin{array}{cc}
0.03 & 0 \\
0 & 0.01
\end{array}\right], & C=\left[\begin{array}{cc}
0.12 & 0 \\
0 & 0.18
\end{array}\right],
\end{array}
$$

and

$$
0.2 \leq h(t)=0.2+0.3 \sin ^{2}(t) \leq 0.5 \text {. }
$$

Let us choose

$$
\begin{aligned}
& P=\left[\begin{array}{ll}
8 & 0 \\
0 & 7
\end{array}\right], \quad Q=\left[\begin{array}{ll}
4 & 0 \\
0 & 4
\end{array}\right], \quad R=\left[\begin{array}{ll}
1.5 & 0.5 \\
0.5 & 1.5
\end{array}\right], \\
& S=\left[\begin{array}{cc}
0.12 & 0 \\
0 & 0.1
\end{array}\right], \quad U=\left[\begin{array}{ll}
1.2 & 0.1 \\
0.1 & 1.2
\end{array}\right] .
\end{aligned}
$$

Under the above assumptions, all eigenvalues of the LMI described by (3.1) are $\lambda_{\max }(\Omega) \leq-0.0969$ by using MATLAB-Simulink.

As a result, condition (3.1) holds, which implies that the zero solution of system (4.1) with (4.2) is asymptotically stable according to Theorem 3.1.

Example 4.2 As a special case of system (2.1), consider the following fractional neutral system with variable delay:

$$
{ }_{t_{0}} D_{t}^{q}(x(t)-C x(t-h(t)))=A_{0} x(t)+A_{1} x(t-h(t))+B \int_{t-h(t)}^{t} x(s) d s, \quad t \geq 0
$$

where $q \in(0,1), x(t)=\left[x_{1}(t), x_{2}(t)\right]^{T}$,

$$
\begin{array}{ll}
A_{0}=\left[\begin{array}{cc}
-6 & 0 \\
2 & -1
\end{array}\right], & A_{1}=\left[\begin{array}{cc}
1 & 0.3 \\
0.2 & 0
\end{array}\right], \\
B=\left[\begin{array}{cc}
0.02 & 0 \\
0 & 0.1
\end{array}\right], & C=\left[\begin{array}{cc}
0.14 & 0 \\
0 & 0.16
\end{array}\right],
\end{array}
$$

and

$$
0.4 \leq \tau_{1}(t)=0.4+0.2 \sin ^{2}(t) \leq 0.6 .
$$


Let us choose

$$
P=\left[\begin{array}{ll}
7 & 0 \\
0 & 5
\end{array}\right], \quad Q=\left[\begin{array}{ll}
4 & 1 \\
1 & 2
\end{array}\right], \quad S=\left[\begin{array}{ll}
2.4 & 0.3 \\
0.3 & 2.4
\end{array}\right], \quad U=\left[\begin{array}{cc}
1 & 0.2 \\
0.2 & 1
\end{array}\right] .
$$

Under the above assumptions, all eigenvalues of the LMI described by (3.8) are $\lambda_{\max }(\Sigma) \leq-1.0417$ by using MATLAB-Simulink.

As a result, condition (3.8) holds, which implies that the zero solution of system (4.3) with (4.4) is asymptotically stable according to Theorem 3.2.

Example 4.3 As a special case of system (2.1), consider the following fractional neutral system with variable delay:

$$
{ }_{t_{0}} D_{t}^{q}(x(t)-C x(t-h(t)))=A_{0} x(t)+A_{1} x(t-h(t))+B \int_{t-h(t)}^{t} x(s) d s, \quad t \geq 0,
$$

where $q \in(0,1), x(t)=\left[x_{1}(t), x_{2}(t)\right]^{T}$,

$$
\begin{aligned}
& A_{0}=\left[\begin{array}{cc}
-10 & -0.2 \\
-0.6 & -1
\end{array}\right], \quad A_{1}=\left[\begin{array}{ll}
1.4 & 0.4 \\
0.8 & 0.2
\end{array}\right], \\
& B=\left[\begin{array}{cc}
0.9 & 0 \\
0 & 0.1
\end{array}\right], \quad C=\left[\begin{array}{cc}
0.12 & 0 \\
0 & 0.2
\end{array}\right],
\end{aligned}
$$

and

$$
\begin{cases}r(t)=0.1+0.2 \sin ^{2}(t) \leq 0.3, & \text { if } t \in I=\bigcup_{k \geq 0}[2 k \pi,(2 k+1) \pi], \\ r(t)=0, & t \in \mathfrak{R}^{+} / I .\end{cases}
$$

Let us choose

$$
P=\left[\begin{array}{cc}
5.8 & 0 \\
0 & 1
\end{array}\right], \quad S=\left[\begin{array}{cc}
1.4 & 0.5 \\
0.5 & 1.2
\end{array}\right], \quad U=\left[\begin{array}{cc}
1 & 0.3 \\
0.3 & 0.5
\end{array}\right] .
$$

Under the above assumptions, all eigenvalues of the LMI described by (3.12) are $\lambda_{\max }(\Xi) \leq-0.0352$ by using MATLAB-Simulink.

As a result, condition (3.12) holds, which implies that the zero solution of system (4.5) with (4.6) is asymptotically stable according to Theorem 3.3.

When the theoretical solutions of the above examples (Examples 4.1, 4.2, and 4.3) are examined, it is seen that the zero solution of the considered systems in the examples is stable after a certain time interval under different initial conditions. These are confirmed by the related simulation results (Figs. 1, 2, 3).

When the results of this study are compared with the results of similar studies in the literature, time delay was taken constant in the examples given in the studies which were published before [13 and 16]. The theoretical results in these studies were not supported by simulation studies. However, this proposed study is more general, and the time delay depends on the variable and the theoretical results are supported by simulations. 


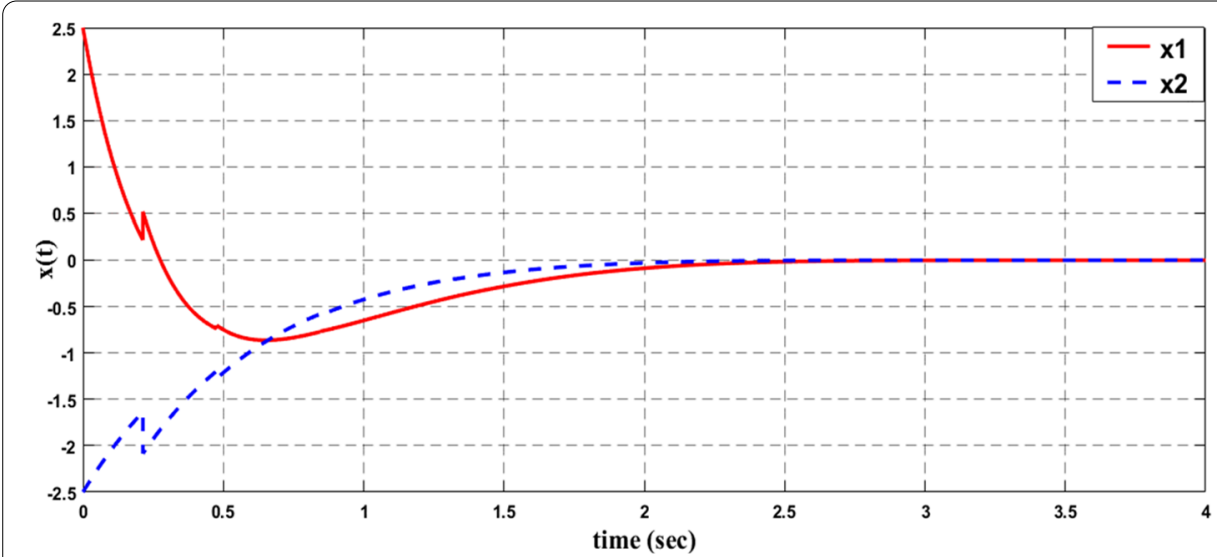

Figure 1 The simulation of Example 4.1 for (4.2)

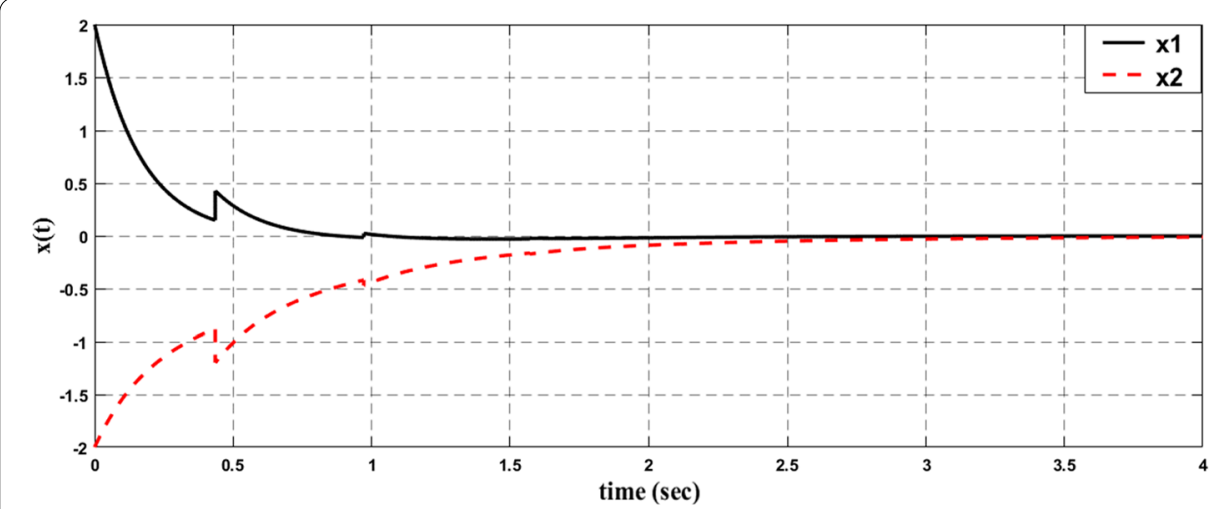

Figure 2 The simulation of Example 4.2 for (4.4)

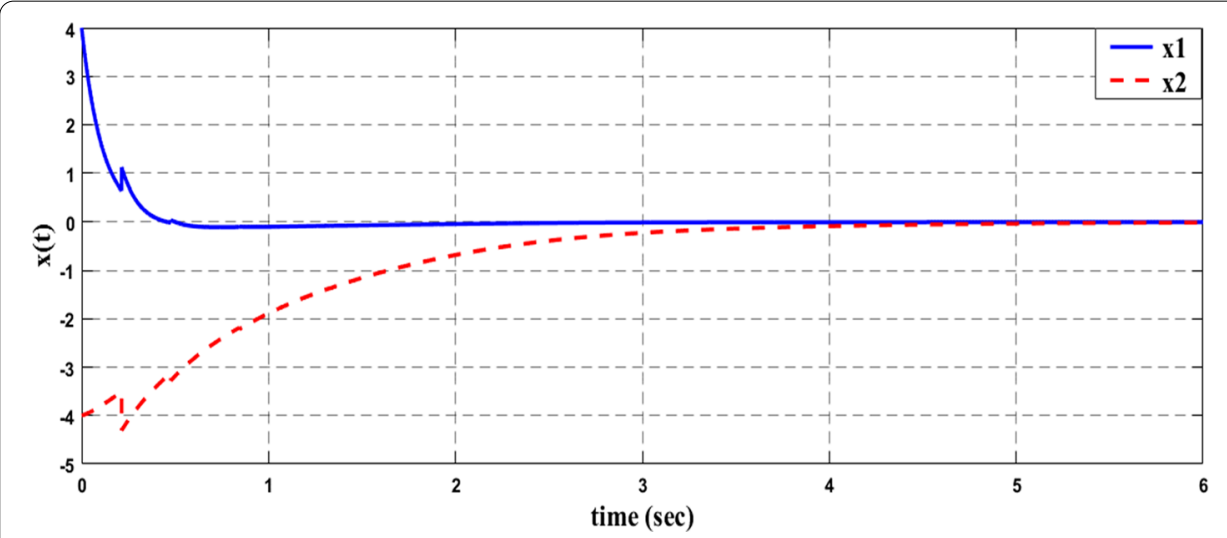

Figure 3 The simulation of Example 4.3 for (4.6)

\section{Conclusions}

In this paper, asymptotic stability of Riemann-Liouville fractional neutral systems with variable delays has been investigated and some new sufficient conditions have been proposed. The obtained results are described by constructing appropriate Lyapunov func- 
tional and formulating in the form of LMIs, which are convenient and feasible to test the stability. The proposed met hod avoids computing Riemann-Liouville fractional-order derivatives of the Lyapunov functionals. When compared with the stability criteria in the related literature, our criteria are simple and suitable for application. Three numerical examples are given with their simulations (Fig. 1, Fig. 2, and Fig. 3) to demonstrate the effectiveness of the stability criteria of the considered system. It is observed that the numerical examples and simulation results verify the efficiency and accuracy of the theoretical results of this paper. The results of this study can be solved numerically by some recent methodologies such as those discussed in [39] and [40]. Consequently, the obtained results in this study extend and generalize the existing ones in the literature.

Funding

There is no funding for this article.

Availability of data and materials

Data sharing is not applicable to this article as no data sets were generated or analyzed during the current study.

Competing interests

The author declares that there is no conflict of interests regarding the publication of this paper.

\section{Authors' contributions}

The author read and approved the current manuscript.

\section{Publisher's Note}

Springer Nature remains neutral with regard to jurisdictional claims in published maps and institutional affiliations.

Received: 22 May 2019 Accepted: 3 October 2019 Published online: 16 October 2019

References

1. Agarwal, R.P., Benchohra, M., Hamani, S.: A survey on existence results for boundary value problems of nonlinear fractional differential equations and inclusions. Acta Appl. Math. 109(3), 973-1033 (2010)

2. Baleanu, D., Jajarmi, A., Asad, J.H.: Classical and fractional aspects of two coupled pendulums. Rom. Rep. Phys. 71(1), Article ID 103 (2019)

3. Baleanu, D., Ranjbar, A.N., Sadati, S.J.R., Delavari, H., Abdeljawad, T., Gejji, V.: Lyapunov-Krasovskii stability theorem for fractional systems with delay. Rom. J. Phys. 56(5-6), 636-643 (2011)

4. Baleanu, D., Sajjadi, S.S., Jajarmi, A., Asad, J.H.: New features of the fractional Euler-Lagrange equations for a physical system within non-singular derivative operator. Eur. Phys. J. Plus 134, Article ID 181 (2019)

5. Chen, L., He, Y., Chai, Y., Wu, R.: New results on stability stabilization of a class of nonlinear fractional-order systems. Nonlinear Dyn. 75(4), 633-641 (2014)

6. Deng, J., Deng, Z.: Existence of solutions of initial value problems for nonlinear fractional differential equations. Appl. Math. Lett. 32, 6-12 (2014)

7. Deng, W., Li, C., Lu, J.: Stability analysis of linear fractional differential system with multiple time delays. Nonlinear Dyn. 48(4), 409-416 (2007)

8. Diethelm, K.: The Analysis of Fractional Differential Equations: An Application-Oriented Exposition Using Differential Operators of Caputo Type. Springer, Berlin (2010)

9. Duarte-Mermoud, M.A., Aguila-Camacho, N., Gallegos, J.A., Castro-Linares, R.: Using general quadratic Lyapunov functions to prove Lyapunov uniform stability for fractional order systems. Commun. Nonlinear Sci. Numer. Simul. 22 650-659 (2015)

10. Hale, J., Lunel, S.V.: Introduction to Functional Differential Equations. Springer, New York (1993)

11. Hajipour, M., Jajarmi, A., Baleanu, D., Sun, H.G.: On an accurate discretization of a variable-order fractional reaction-diffusion equation. Commun. Nonlinear Sci. Numer. Simul. 69, 119-133 (2019)

12. Kilbas, A.A., Srivastava, H.M., Trujillo, J.J.: Theory and Application of Fractional Differential Equations. Elsevier, New York (2006)

13. Li, H., Zhou, S, Li, H.: Asymptotic stability analysis of fractional-order neutral systems with time delay. Adv. Differ. Equ. 2015, Article ID 325 (2015)

14. Liu, K., Jiang, W.: Stability of fractional neutral systems. Adv. Differ. Equ. 2014, Article ID 78 (2014)

15. Liu, S., Jiang, W., Li, X., Zhou, X.F.: Lyapunov stability analysis of fractional nonlinear systems. Appl. Math. Lett. 51, 13-19 (2016)

16. Liu, S., Wu, X., Zhang, Y.-J., Yang, R.: Asymptotical stability of Riemann-Liouville fractional neutral systems. Appl. Math. Lett. 69, 168-173 (2017)

17. Liu, S., Wu, X., Zhou, X.F., Jiang, W.: Asymptotical stability of Riemann-Liouville fractional nonlinear systems. Nonlinear Dyn. 86(1), 65-71 (2016)

18. Liu, S., Zhou, X.F., Li, X., Jiang, W.: Stability of fractional nonlinear singular systems its applications in synchronization of complex dynamical networks. Nonlinear Dyn. 84(4), 2377-2385 (2016) 
19. Liu, S., Zhou, X.F., Li, X., Jiang, W.: Asymptotical stability of Riemann-Liouville fractional singular systems with multiple time-varying delays. Appl. Math. Lett. 65, 32-39 (2017)

20. Lu, J.G., Chen, G.: Robust stability and stabilization of fractional-order interval systems: an LMI approach. IEEE Trans. Autom. Control 54(6), 1294-1299 (2009)

21. Matignon, D.: Stability results on fractional differential equations with applications to control processing. In: Proceedings of IMACS-SMC, pp. 963-968 (1996)

22. Mohammadi, F., Moradi, L., Baleanu, D., Jajarmi, A.: A hybrid functions numerical scheme for fractional optimal control problems: application to non-analytic dynamical systems. J. Vib. Control 24(21), 5030-5043 (2018)

23. Podlubny, l.: Fractional Differential Equations. Academic Press, New York (1999)

24. Qian, D., Li, C., Agarwal, R.P., Wong, P.J.Y.: Stability analysis of fractional differential system with Riemann-Liouville derivative. Math. Comput. Model. 52, 862-874 (2010)

25. Sabatier, J., Moze, M., Farges, C.: LMI stability conditions for fractional order systems. Comput. Math. Appl. 59(5), 1594-1609 (2010)

26. Wang, J., LV, L., Zhou, Y.: New concepts and results in stability of fractional differential equations. Commun. Nonlinear Sci. Numer. Simul. 17(6), 2530-2538 (2012)

27. Zhou, Y., Jiao, F.: Existence of mild solutions for fractional neutral evolution equations. Comput. Math. Appl. 59(3), 1063-1077 (2010)

28. Zhang, H., Ye, R., Cao, J., Ahmed, A., Li, X., Ying, W.: Lyapunov functional approach to stability analysis of Riemann-Liouville fractional neural networks with time-varying delays. Asian J. Control 20(5), 1938-1951 (2018)

29. Altun, Y., Tunç, C.: On exponential stability of solutions of nonlinear neutral differential systems with discrete and distributed variable lags. Nonlinear Stud. 26(2), 455-466 (2019)

30. Balasubramaniam, P., Krishnasamy, R., Rakkiyappan, R.: Delay-dependent stability of neutral systems with time-varying delays using delay-decomposition approach. Appl. Math. Model. 36, 2253-2261 (2012)

31. Phat, V.N., Khongtham, Y., Ratchagit, K.: LMl approach to exponential stability of linear systems with interval time-varying delays. Linear Algebra Appl. 436, 243-251 (2012)

32. Tunç, C., Altun, Y:: Asymptotic stability in neutral differential equations with multiple delays. J. Math. Anal. 7(5), 40-53 (2016)

33. Xiong, L., Zhong, S., Tian, J.: New robust stability condition for uncertain neutral systems with discrete and distributed delays. Chaos Solitons Fractals 42, 1073-1079 (2009)

34. Faieghi, M., Kuntanapreeda, S., Delavari, H., Baleanu, D.: LMI-based stabilization of a class of fractional-order chaotic systems. Nonlinear Dyn. 72(1-2), 301-309 (2013)

35. Faieghi, M., Mashhadi, S.K.M., Baleanu, D.: Sampled-data nonlinear observer design for chaos synchronization: a Lyapunov-based approach. Commun. Nonlinear Sci. Numer. Simul. 19(7), 2444-2453 (2014)

36. Faieghi, M.R., Kuntanapreeda, S., Delavari, H., Baleanu, D.: Robust stabilization of fractional-order chaotic systems with linear controllers: LMI-based sufficient conditions. J. Vib. Control 20(7), 1042-1051 (2014)

37. Mobayen, S., Baleanu, D., Tchier, F.: Second-order fast terminal sliding mode control design based on LMI for a class of non-linear uncertain systems and its application to chaotic systems. J. Vib. Control 23(18), 2912-2925 (2017)

38. Wu, G.C., Baleanu, D., Luo, W.H.: Lyapunov functions for Riemann-Liouville-like fractional difference equations. Appl. Math. Comput. 314, 228-236 (2017)

39. Hajipour, M., Jajarmi, A., Baleanu, D.: On the accurate discretization of a highly nonlinear boundary value problem. Numer. Algorithms 79(3), 679-695 (2018)

40. Hajipour, M., Jajarmi, A., Malek, A., Baleanu, D.: Positivity-preserving sixth-order implicit finite difference weighted essentially non-oscillatory scheme for the nonlinear heat equation. Appl. Math. Comput. 325, 146-158 (2018)

\section{Submit your manuscript to a SpringerOpen ${ }^{\circ}$ journal and benefit from:}

- Convenient online submission

- Rigorous peer review

- Open access: articles freely available online

- High visibility within the field

- Retaining the copyright to your article

Submit your next manuscript at $\gg$ springeropen.com 